ORIGINAL ARTICLE

\title{
Washing machine related injuries in children: a continuing threat
}

\author{
B L Warner, B D Kenney, M Rice
}

Injury Prevention 2003;9:357-360

See end of article for authors' affiliations ......................

Correspondence to: Barbara L Warner, Toledo Children's Hospital, Pediatric Trauma Services, 2142 North Cove Boulevard, Toledo, $\mathrm{OH}$ 43606, USA; barbara.warner@ promedica.org

\begin{abstract}
Objective: To describe washing machine related injuries in children in the United States.
Methods: Injury data for $\mathbf{4 9 6}$ washing machine related injuries documented by the Consumer Product Safety Commission's National Electronic Injury Surveillance System and death certificate data files were analyzed. Gender, age, diagnosis, body part injured, disposition, location and mechanism of injury were considered in the analysis of data.

Results: The upper extremities were most frequently injured in washing machine related injuries, especially with wringer machines. Fewer than $10 \%$ of patients required admission, but automatic washers accounted for most of these and for both of the deaths. Automatic washer injuries involved a wider range of injury mechanism, including 23 children who fell from the machines while in baby seats.

Conclusions: Though most injuries associated with washing machines are minor, some are severe and devastating. Many of the injuries could be avoided with improvements in machine design while others suggest a need for increased education of potential dangers and better supervision of children if they are allowed access to areas where washing machines are operating. Furthermore, washing machines should only be used for their intended purpose. Given the limitations of educational efforts to prevent injuries, health professionals should have a major role in public education regarding these seemingly benign household appliances.
\end{abstract}

W ashing machines are not often considered dangerous appliances until an injury occurs. A patient treated at our level I trauma center who suffered a brain injury due to a near drowning incident in an automatic washing machine prompted our interest in examining the epidemiology of washing machine related injuries. Injuries related to the wringer mechanisms of washing machines have been described for years in the medical literature, and are still a significant problem. ${ }^{1-11}$ Medical reports describing injuries associated with automatic washers are sparse. We believe new types of injuries have emerged with the replacement of manually operated wringer washing machines by automatic washers.

In this article we describe patterns of injury associated with both wringer and automatic washing machines based on data from the United States Consumer Product Safety Commission (CPSC). The CPSC's National Injury Information Clearinghouse monitors injuries and deaths associated with over 15000 types of consumer products using the death certificate data files and the National Electronic Injury Surveillance System (NEISS). NEISS, established in 1972, collects data from a probability sample of hospital emergency rooms in the United States and its territories. In 2000 the sample included 100 hospital emergency departments of varying size. Emergency departments of children's hospitals represented one fifth of the sample. The data collected from these hospitals was used by the CPSC to estimate the number of washing machine related injuries treated in emergency rooms in the entire nation. ${ }^{12}{ }^{13}$

The CSPC estimates that an estimated 19109 washing machine related injuries occurred involving children under the age of 15 from 1993-2000. Washing machine related injuries accounted for approximately 2388 emergency room visits and 128 hospital admissions per year. Wringer washers accounted for almost $20 \%$ of the total injuries or an estimated 5361 emergency room visits. When separated by year, the number of wringer injuries showed a tendency to decrease from 1993 to 2000 . However, the actual case numbers are too few for the CSPC to determine a statistically valid estimate (personal communication, Thomas Schroeder, 2002).

\section{METHODS}

We analyzed the CSPC reports of 496 patients injured in association with washing machines to determine the types and circumstances of the injuries. Data were obtained for patients injured in association with product codes 0102 (wringer washing machines) and 0126 (washing machines, not specified) from January 1993 to December 2000. Product code 0126 contained data on injuries associated with the typical automatic washing machines found in households and at laundromats. The data for patients under the age of 15 were analyzed for treatment date, age, gender, diagnosis, body part injured, disposition, location of event, other consumer products involved, and comments reported by the hospital. Comments, typically a brief narrative of the circumstances of the incident, were reviewed to define a mechanism of injury. In some cases the mechanism of injury could not be determined and are reported as such. All wringer related injuries were considered a single mechanism. We further analyzed injuries related directly to the operation of the washing machine (primary cause) and injuries that occurred around the washing machine (secondary cause), such as falls. SPSS 10 was used to analyze data and generate the tables and graph. ${ }^{14}$

\section{RESULTS}

A total of 405 automatic washer injuries and 91 wringer washer machine injuries were reported in the data. The age distribution of injuries is shown in fig 1 . The most frequent

Abbreviations: CPSC, Consumer Product Safety Commission; NEISS, National Electronic Injury Surveillance System 


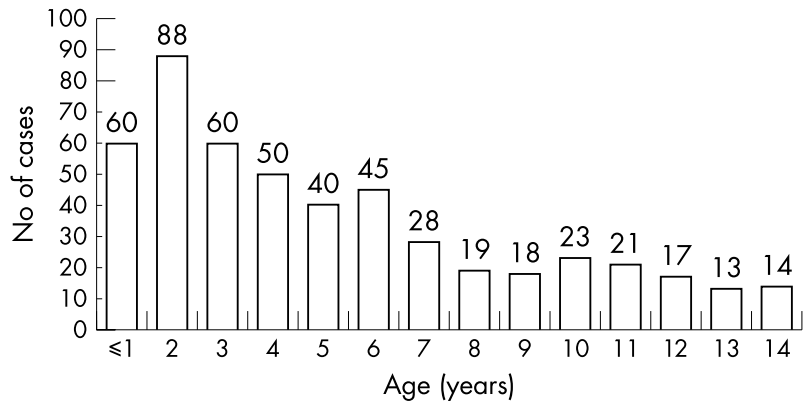

Figure 1 Age distribution of washing machine related injuries.

age of injury was from 1-2 years. The median age was 4 years for automatic washing machines and 5 years for wringer washing machines. Victims were predominantly male with both types of machine $(60.7 \%$ for automatic and $54.9 \%$ for wringers). The most common diagnoses of automatic washing machine related injuries were laceration/puncture (31.1\%), contusion/abrasion/hematoma (25\%), and fracture $(15.3 \%)$. Wringer washing machines had a much narrower range of diagnoses: contusion/abrasion/hematoma were diagnosed in $54.9 \%$ of the cases and crush injuries were reported in $29.7 \%$ (table 1 ).

The body part injured differed between the two types of machines (table 2 ). Nearly all $(96.7 \%)$ of the wringer related injuries occurred in the upper extremities, whereas the injuries from automatic washing machines occurred in a variety of body parts, with the head and face and the upper extremities being the most common. Primary cause injuries involved the upper extremities in $86 \%$ of the cases. Secondary cause injuries involved the head and neck area in $58 \%$ of the cases.

Overall, $93.1 \%$ of the children who suffered from washing machine related injuries were treated and released from the emergency department. Automatic washer injury accounted for the majority of hospitalizations or transfers. Of the children that required hospitalization or were transferred to another facility, $43.3 \%$ had fractures, $20 \%$ had burn injuries, and $13.3 \%$ had crush injuries from wringers. Primary cause injuries resulted in hospitalization for $9.7 \%$ of the cases compared with $3.9 \%$ of secondary cause injuries.

Two deaths were associated with automatic washing machines: one from a washing machine falling on a child and one from drowning in the water filled machine. No deaths were associated with wringer washers.

The location of the incident was recorded in 61/91 wringer washing machine related injuries and in 281/405 automatic washer injuries. In all cases the majority of events occurred at home. Public property, usually laundromats, comprised 7.9\% of the cases for which a location was recorded. These injuries were most often lacerations and contusions/abrasions $(53.9 \%)$, typically of the head and face. No hospitalization resulted from incidents at laundromats.

The most common mechanisms of injury associated with automatic washers included falling or jumping from the appliance (38.5\%), striking the washer $(33.3 \%)$, and putting a body part into a running machine (12.8\%) (table 3 ). When a body part was placed in a running machine, $51.9 \%$ of the children suffered a fracture. These fractures were most often in the lower arm (40.7\%) or the lower leg (18.5\%).

Almost half of primary cause injuries were wringer washer related. The second most common mechanism for this category of injuries was placing a body part in an automatic washing machine. For secondary cause injuries, jumping or falling off the machine and striking the washer were most common (table 3). Some unexpected secondary cause injuries were reported. In a number of cases, children ingested chemicals stored on or near the washing machine. Sodium hypochlorite in particular was associated with ingestions and also with chemical burns of the skin. Several cases were reported in which children were burned by hot liquids left on top of the washer that children spilled onto themselves. Although intentional injury is a possibility in some of these cases, NEISS does not document this information.

Nearly $31 \%$ of the automatic washing machine related injuries involved another product tracked by the CPSC, while only $4.4 \%$ of the wringer related injuries involved another product. One product frequently mentioned was baby carriers or car seats. Twenty three cases were recorded in which a baby fell from the washer while in a car seat or baby carrier: all of these children suffered head or facial injuries. Car seats and baby carriers are second only to flooring in the associated products mentioned in the database.

\section{DISCUSSION}

Our study is the first to examine the injury patterns associated with both automatic and wringer washing machines and demonstrates some hidden dangers and poorly publicized associated injuries. Deaths were rare but devastating, especially in a context that most adults consider safe.

Automatic washers have replaced wringer washers in many United States homes, where the data in this study were collected. Production of wringer washers ceased in the United States in 1983. ${ }^{15}$ Although wringer washers are no longer prevalent in homes in the United States, they are available for purchase through the internet and continue to pose a risk for serious injury. ${ }^{16}$ Wringer washer related injuries are surprisingly frequent in the NEISS data and

\begin{tabular}{|c|c|c|c|}
\hline Diagnosis & Automatic (\%) & Wringer (\%) & Combined (\%) \\
\hline Contusion/abrasion/hematoma & $101(25.0)$ & $50(54.9)$ & $151(30.4)$ \\
\hline Laceration/puncture & $126(31.1)$ & $4(4.4)$ & $130(26.2)$ \\
\hline Fracture & $62(15.3)$ & $2(2.2)$ & $64(12.9)$ \\
\hline Crush & 0 & $27(29.7)$ & $27(5.4)$ \\
\hline Internal organ injury & $31(7.7)$ & 0 & $31(6.3)$ \\
\hline Strain/sprain & $19(4.7)$ & 0 & $19(3.8)$ \\
\hline Burns & $11(2.7)$ & $1(1.1)$ & $12(2.4)$ \\
\hline Dislocation/avulsion/amputation & $12(2.9)$ & $3(3.3)$ & $15(3.0)$ \\
\hline Submersion/drowning/aspiration & $3(0.7)$ & 0 & $3(0.6)$ \\
\hline Concussion & $4(1.0)$ & 0 & $4(0.8)$ \\
\hline Poisoning & $7(1.7)$ & 0 & $7(1.4)$ \\
\hline Other & $29(7.1)$ & $4(4.4)$ & $33(6.6)$ \\
\hline Total & 405 & 91 & 496 \\
\hline
\end{tabular}




\begin{tabular}{|llll|}
\hline \multicolumn{4}{l}{ Table 2 Body parts injured in washing machine related injury } \\
\hline Body part injured & Automatic (\%) & Wringer (\%) & Combined (\%) \\
\hline Upper extremity & $124(30.7)$ & $88(96.7)$ & $212(42.7)$ \\
Head/face/eye/mouth/neck & $183(45.1)$ & $1(1.1)$ & $184(37)$ \\
Lower extremity & $50(12.3)$ & 0 & $50(10)$ \\
$>25 \%$ of body & $14(3.5)$ & $2(2.2)$ & $16(3.2)$ \\
Lower trunk & $16(4.0)$ & 0 & $16(3.2)$ \\
Upper trunk & $10(2.5)$ & 0 & $10(2.0)$ \\
Internal (aspiration) & $1(0.2)$ & 0 & $1(0.2)$ \\
Not stated & $2(0.5)$ & 0 & $2(0.4)$ \\
Total & 405 & 91 & 496 \\
\hline Note: percentages may not total 100 due to rounding. & & \\
\hline
\end{tabular}

account for almost one fifth of the injuries and almost half of primary cause injuries. Fewer wringer injuries were reported in the second half of the data (1997-2000), however, the case numbers are too few for the CPSC to calculate a valid estimate. As newer automatic washers replace old wringer washers, the NEISS data may continue to show a decrease in wringer injuries. We speculate that wringer washers are widely utilized in non-industrialized nations and may account for a higher percent of injuries. Public health education is needed in areas where wringers are still common.

Some of the features that make automatic washers superior to hand washing and wringing also carry the potential to cause serious injuries. Heated water can cause burns. Electrically driven motors create mechanical forces during agitation and spinning strong enough to fracture or amputate a limb. Safety features have been developed that mitigate some of the risks from automatic washing machines including locking lid mechanisms and tubs that automatically stop agitating when the lid is opened. However, these mechanisms are present only in later models and are not foolproof: machines fill with water while the lid is open, spinning and agitation continue for a few seconds after the lid is opened, and in some cases the locking mechanism is easily circumvented. In fact, the most severe injuries in this dataset (fractures, amputations, and drowning) occurred while the appliance was in operation. Parents must recognize that the potential for serious injury or drowning exists despite the safety features. Consumers should demand that manufacturers create better safety features based on injury data. For automatic washers, safety mechanisms that will not allow the washer to fill with water, spin, or agitate until the lid is locked would prevent many of the primary injuries identified in the data. Wringer washers should have protective covers that prevent fingers and arms from accessing the rollers. Safety features could be developed to stop the wringers when reverse tension is placed on the clothing that is moving through the rollers. Many of the wringer injury comments suggested that extremities were caught in the clothing and pulled through the wringers.

Injury patterns not necessarily related to washing machines (secondary cause injuries) were also evident in the database. Striking the washer was a common mechanism of injury. Although injuries from falls and striking objects can occur in other areas of the home, our study demonstrates that many injuries do take place around the washing machine. Some serious injuries occurred when washing machines were used for purposes other than laundry. Burns occurred when washing machines were used as a cooking surface. Caustic cleaning compounds stored on top of the washer were pulled off by children and caused chemical burns or toxic ingestions. These hazards have not been evident in previous studies of injuries in the home and better parental awareness is needed. ${ }^{17} 18$

Many secondary cause injuries were due to children jumping or falling from the washer, including children seated in car or baby seats, which were placed on a washing machine. Hulka and Piatt noted that some parenting publications recommend placing an inconsolable, colicky baby in a car seat on a running washing machine or dryer to soothe a crying infant. ${ }^{19}$ Parents should be cautioned concerning the dangers of leaving a baby unsupervised on any raised surface, but especially on a vibrating washing machine. Car seat manufacturers should emphasize the danger of using their product in a manner other than for its intended purpose.

Several limitations of this study deserve consideration. The only injuries included in the NEISS data were those severe enough to warrant an emergency center visit, which may lead to an under-representation of the incidence of injuries in general, and an over-estimation of the severity of injuries. The number of visits to physician offices for washing machine injuries is unknown. Another limitation is that no data are available to differentiate top loading washers from front loading washers, which may have different injury patterns. It would be unlikely that a child could drown in a front loading washing machine since the door must remain

Table 3 Common mechanisms of washing machine related injury

\begin{tabular}{llll}
\hline Mechanism & Automatic (\%) & Primary (\%) & Secondary (\%) \\
\hline Fell or jumped off washer & $156(38.5)$ & 0 & $156(50.3)$ \\
Struck washer & $135(33.3)$ & 0 & $135(43.5)$ \\
Put body part into running washer & $52(12.8)$ & $52(30)$ & 0 \\
Hit by falling lid & $23(5.7)$ & $23(12.4)$ & 0 \\
Pulled item off of washer onto self/item fell & $15(3.7)$ & 0 & $15(4.8)$ \\
Drowned/fell into washer & $3(0.7)$ & $3(1.6)$ & 0 \\
Other/could not determine & $21(5.2)$ & $17(9.1)$ & $4(1.3)$ \\
Wringer & 0 & $91(48.9)$ & 0 \\
Total & 405 & 186 & 310 \\
\hline Note: percentages may not total 100 due to rounding. & & \\
\hline
\end{tabular}




\section{Key points}

- Serious injuries and deaths can occur related to washing machines.

- Wringer washers continue to be a factor in childhood injuries.

- Injuries occur predominantly in the 1-2 year age group.

- Automatic washing machines are associated with a wider range of injuries.

- Use of washing machines should be restricted to their intended purpose.

- Design changes are needed to improve the safety of residential washing machines.

closed for the tub to hold water, however, front loading machines may increase the risk of upper extremity injury if they allow easier access for toddlers. Finally, these data were collected in the United States so that generalization of these conclusions to the international community may not be justified.

In summary, wringer washing machines, although less commonly used, are still associated with a significant number of injuries to children and injuries due to automatic washing machines occur despite the safety features incorporated in modern designs. Some injuries could be avoided by design change, but others can only be prevented by better supervision of children. There is some evidence from a recent study that inadequate supervision of children was a common factor in injury deaths. ${ }^{20}$ Understanding that the effectiveness of parental supervision has not been well quantified, ${ }^{20}$ we hope that better supervision of children and limited access to the washing machine may prevent some of these injuries. Until we find more effective injury prevention methods, health care professionals have a role in public education to heighten awareness of the potential dangers of washing machines, especially when used for other than their intended purpose. Parenting publications should include warnings about injuries associated with washing machines and should specifically prohibit rather than promote the practice of placing infants on machines for the purpose of soothing them. Future research should monitor the effectiveness of safety features as older washing machines are replaced with newer models. Further quantification of circumstances surrounding injuries may lead to better injury prevention approaches.

\section{ACKNOWLEDGEMENTS}

We wish to thank Ida Harper-Brown and Vicky Leonard, technical information specialists from the National Injury Information Clearinghouse for their technical support in compiling data from the NEISS database. We also would like to thank Thomas Schroeder for his statistical advice.

\section{Authors' affiliations}

B L Warner, M Rice, Toledo Children's Hospital

B D Kenney, Columbus Children's Hospital

\section{REFERENCES}

1 Allen JE, Beck AR, Jewett TC Jr. Wringer injuries in children. Arch Surg 1968;97:194-7.

2 Cabbabe EB, Korock SW. Wringer washer injuries in children. Ann Plast Surg 1983;10:135-42.

3 Duncan RE, Moseley T. Wringer injuries in children. An analysis of 300 cases. J Fla Med Assoc 1969;56:106-7.

4 Duncan R, Moseley T. Wringer injuries. Medical Times 1970;98:196-7.

5 Franz JL, Root HD. Upper extremity wringer injury. Vasc Surg 1975;9:302-7.

6 Garrick JA. Wringer injuries. Minn Med 1967;50:195-201.

7 McCulloch JH, Boswick JA Jr, Jonas R. Household wringer injuries: a threeyear review. J Trauma 1973;13:1-8.

8 McGee G E, Diller DB. Wringer injuries of extremities. South Med J 1983;76:304-6.

9 Sperling RL. Wringer injuries. Rev Surg 1971;28:88-90.

10 Stone HH, Cantwell DV, Fulenwider JT. Wringer arm injuries. J Pediatr Surg 1976;11:375-9.

11 Weinshel S, Greydanus W, Glicklich M. Wringer washing machine injuries: criteria for obtaining radiological studies. J Trauma 1986;26:1132-3.

12 US Consumer Product Safety Commission. Guide to public information. CPSC web site. Available at: www.cpsc.gov/about/guide.html (accessed on 15 October 2001).

13 Centers for Disease Control and Prevention. NEISS: The National Electronic Injury Surveillance System, a tool for researchers. US Consumer Product Safety, Division of Hazard and Injury Data web site. Available at: http// www.cdc.gov/Neiss/2000d015.pdf (accessed on 14 October 2001).

14 SPSS. SPSS 10.0 [computer program]. Version 10. Chicago, IL: SPSS Science Inc, 2000.

15 Maytag Corporation. About Maytag Corporation, Maytag timeline. Maytag Corporation web site. Available at: www.maytag.com/mths/our_company/ default.jsp?partner = none (accessed on 27 November, 2001).

16 Lehman's. Lehman's Speed Queen wringer washer. Available at: www.lehmans.com/cgibin/ncommerace3/ExecMacro/lehmans/Search.dw/ report? searchtext = wringer+washers (accessed on 25 June 2002).

17 Dershewitz RA, Christophersen ER. Childhood household safety. An overview. American Journal of Diseases of Children 1984;138:85-8.

18 Hu X, Wesson D, Kenney B. Home injuries to children. Can J Public Health (Revue Canadienne de Sante Publique) 1993;84:155-8.

19 Hulka F, Piatt J. An infant in a car seat on a washing machine: epidural hematoma. Pediatrics 1994;94(4 pt 1):556-7.

20 Landen MG, Baver U, Kohn M. Inadequate supervision as a cause of injury deaths among young children in Alaska and Louisiana. Pediatrics 2003;111:328-31. 